\title{
A Review on the Role of Chemical Nature of Fluoride on Human Health and Environment
}

\author{
${ }^{1(a)}$ R. Hema Krishna, ${ }^{1(b)}$ V. Subhashini, ${ }^{2}$ A.V.V.S Swamy \\ ${ }^{1(a)}$ Department of Chemistry, University of Toronto, Ontario, Canada \\ 1(b), 2 Departments of Environmental Sciences, Acharya Nagarjuna University, NagarjunaNagar \\ Guntur (Dist.) Andhra Pradesh, India \\ hkravuri32@gmail.com
}

\begin{abstract}
The review of this article is focusing on role of chemical nature of fluoride on human health and environment. Fluoride has both positive and negative effects on human health and environment. However this positive effect is felt when the fluoride concentration is low. At higher concentration the negative affects of fluoride far out way its positive effects. Millions of people all over the world presently suffer from a debilitating bone disease called skeletal fluorosis and also from dental fluorosis. Apart from dental and skeletal fluorosis fluoride also affects many vital organs of the body. Scientists and Doctors across the world have worked extensively on the health impacts of fluoride on humans and animals and found that fluoride has tremendous impact on the living system. The only remedy is prevention by keeping fluoride intake within the safe limits. Fluoride poisoning can be prevented or minimized by using alternative water sources, removing excess fluoride, and improving the nutritional status of the population at risk. Clinical data indicate that adequate calcium intake is clearly associated with a reduced risk of dental fluorosis. Vitamin $C$ may also act as a safeguard against the risk. Therefore, measures to improve the nutritional status of an affected population, particularly in children, appear to be an effective supplement for an antidote against fluorosis.
\end{abstract}

Keywords: Fluoride, health problems, Dental fluorosis, skeletal fluorosis, Non skeletal fluorosis

\section{INTRODUCTION}

Fluoride has both positive and negative effects on human health, but there is a narrow range between intakes that are associated with some adverse effects. Fluoride was first used to fight dental cavities in the 1940s, its effectiveness defended on two grounds: Fluoride inhibits enzymes that breed acidproducing oral bacteria whose acid eats away tooth enamel. This observation is valid, but some scientists now believe that the harmful impact of fluoride on other useful enzymes far outweighs the beneficial effect on caries prevention. Fluoride ions bind with calcium ions, strengthening tooth enamel as it forms in children. Many researchers now consider this more of an assumption than fact, because of conflicting evidence from studies in India and several other countries over the past 10 to 15 years [1]. Nevertheless, agreement is universal that excessive fluoride intake leads to loss of calcium from the tooth matrix, aggravating cavity formation throughout life rather than remedying it, and so causing dental fluorosis. Severe, chronic and cumulative overexposure can cause the incurable crippling of skeletal fluorosis [2].

Fluorosis is an incapacitable (crippling) and painful disease caused due to excessive intake of fluoride, a compound of fluorine. Fluoride can inter in the body through drinking water, foods items, dental products, drugs, dusts and fumes of fluorides from industries using salts and hydrofluoric acid. About 25 countries all over the world are affected by fluorosis. In India at least 18 states are in alarming condition with fluorosis out of which 5 states are in severe endemic phase. Almost 50 to $100 \%$ districts of Andhra Pradesh, Tamil Nadu, Uttar Pradesh, Rajasthan and Gujarat are in endemic phase. Among the water quality parameters, fluoride ion exhibits unique properties as its concentration in optimum dose in drinking water is advantageous to health and if the concentration exceeds the limit, this affects the health. High fluoride concentration in the ground water and surface water in many parts of the world is a cause of great concern. The main source of fluoride in ground water is fluoridebearing rocks such as fluorspar, fluorite, cryolite, fluorapatite and hydroxylapatite. Also the content in ground water is a function of many factors such as availability and solubility of fluoride minerals, velocity of flowing water, $\mathrm{pH}$, and temperature, concentrations of calcium and bicarbonate ions in 


\section{R. Hema Krishna et al.}

water [3]. Due to its strong electro negativity, fluoride is attracted to positively charged calcium in teeth and bones. Major health problems caused by fluoride are dental fluorosis, teeth mottling, skeletal fluorosis and deformation of bones in children as well as adults. Excess fluoride affects plants and animals also. The effect on agriculture was also evident due to inhibition on plant metabolism leading to necrosis, needle scratch and tip burn diseases. In animals also prominent symptoms of fluorosis were observed. In human beings, effects on dental and skeletal tissues can occur in adolescents and young adults and even in children under 10 years of age among communities exposed to high levels of fluoride. It can interfere with carbohydrates, lipids, protein, vitamins, enzymes and mineral metabolism when the dosage is high. Skeletal deformation and weakening of joints are typical forms of fluoride at high levels of fluoride intake. Fluoride is primarily excreted in urine. The severity of injury is determined by duration of fluoride exposure and concentration. Fluoride concentrations in ground water in India vary significantly. In some parts of India, fluoride levels are below $0.5 \mathrm{mg} / \mathrm{L}$, while in other places, fluoride levels are as high as $30 \mathrm{mg} / \mathrm{l}$. According to WHO, permissible limit for fluoride in drinking waters is $1.5 \mathrm{mg} / \mathrm{l}$. WHO has set a range of allowable concentration for fluoride indrinking water for a region depending on its climatic conditions, because the amount of water consumed and consequently the amount of fluoride ingested is being influenced primarily by the air temperature. India was one of the worst fluorosis affected countries, with large number of people suffering. This is because a large number of Indians Depend on groundwater for drinking purposesand water at many places is rich in fluoride [4]. In India 62 million people including 6 million children are estimated to have serious health problems due to consumption of fluoride contaminated water .The main source of fluoride in groundwater is the rocks which are rich in fluoride. Most of the people affected by high fluoride concentration in groundwater live in the tropical countries where the per capita consumption of water is more because of the prevailing climate. Some regions in north western and southern India are heavily affected with fluorosis. Similarly, the rocks in southern India are rich with fluoride which forms the major reason for fluoride contamination in groundwater, and the granites in the districts of Andhra Pradesh contain much higher fluoride than the world average fluoride concentration of $810 \mathrm{mg} / \mathrm{kg}$. Fluorosis was first detectedin India, among cattle and humans in Andhra Pradesh .In India, approximately 60-65 million people drink fluoride contaminated groundwater, and the number affected by fluorosis is estimated at 2.5-6 million, predominately children[5-6]. In India, the excessive presence of fluorides in groundwater is present in nearly 177 districts covering 19 states. The presence of fluoride in drinking water has dual significance. At lower concentrations, it guards our teeth against cavities [7-8] but at higher concentrations imparts 'fluorosis' in varying proportions .Of late, excess fluoride in drinking water is reported from more than 35 countries around the globe with India and China, as seen in Figure 1, being the worst affected

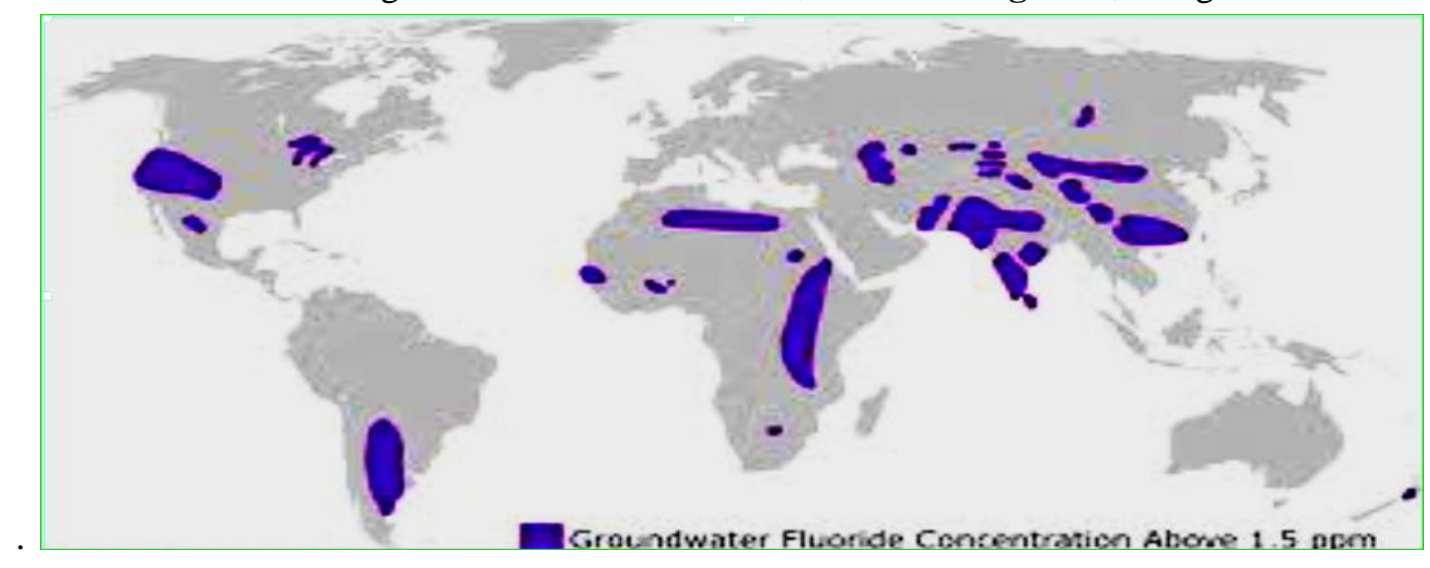

Figure1. Fluoride affected areas in the world depicted with blue

In countries like India, the severe contamination of drinking water with excess fluoride, acquired the dimensions of a socio-economic rather than a public health problem triggering defluoridation research. The World Health Organisation has specified the tolerance limit of fluoride content of drinking water as $1.5 \mathrm{mg} / \mathrm{L}$. Fluoride is attracted by positively charged calcium in teeth and bones due to its strong electro-negativity, which results in dental, skeletal, and non-skeletal forms of fluorosis, in children as well as adults. Fluoride normally enters the environment and human body through water, food, industrial exposure, drugs, cosmetics, etc., however, drinking water is the single major source of daily intake [9]. 


\section{OCCURRENCE OF FLUORIDE}

The fluoride contains in mineral soils is as shown in Table1.Besides rocks and soil, food items especially agricultural produce are heavily contaminates with fluoride, which entrance into the human body through various food items[10]. Fluoride contents indifferent food items have been shown in the Table 2.The fluoride level in industrial emissions and wastewater were exhibited in Table 3. The occurrence of fluoride in excess of $1.5 \mathrm{mg} / 1$ and same information is as shown in Table 4. The permissible limits of fluoride concentration in drinking water prescribed by various organizations are shown in Table 5

Table1. Fluoride Content in Minerals Soils [11]

\begin{tabular}{|l|l|}
\hline \multicolumn{1}{|c|}{ Minerals } & \\
\hline Meteorites & $28-30$ \\
\hline Dunite & 12 \\
\hline Basalt & 100 \\
\hline High Calcium & 520 \\
\hline Granite & --- \\
\hline Alkali rocks & $1200-8500$ \\
\hline Shale & 740 \\
\hline Sand stone & 270 \\
\hline Deep seaa clays & 1300 \\
\hline Deep sea carbonates & 540 \\
\hline
\end{tabular}

Table2. Fluoride Content in Agricultural Crops and Other Edible Items [11]

\begin{tabular}{|c|c|c|c|c|}
\hline \multirow[t]{2}{*}{ Food Items } & \multicolumn{4}{|c|}{ Fluoride in $\mathrm{mg} / \mathrm{L}$} \\
\hline & $\begin{array}{c}\text { Sengupta \& Pal } \\
(1971)\end{array}$ & $\begin{array}{c}\text { Lakadwala \& } \\
\text { Punekar (1973) }\end{array}$ & $\begin{array}{c}\text { Chari et al. } \\
(1975)\end{array}$ & $\begin{array}{c}\text { Rajya Laxmi } \\
(1982)\end{array}$ \\
\hline Wheat & 4.60 & $2.59-3.30$ & -- & - \\
\hline Rice & 5.90 & $3.27-14.03$ & 2.90 & - \\
\hline Bajara & -- & $1.72-2.23$ & 2.82 & 74.00 \\
\hline Soyabean & 4.00 & -- & -- & -- \\
\hline Red gram dal & 3.70 & $2.34-4.84$ & - & -52.80 \\
\hline Cabbage & 3.30 & $1.28-2.29$ & - & -- \\
\hline Lettuce & 5.70 & & -- & - \\
\hline Tomato & 3.40 & $1.00-2.08$ & 0.33 & - \\
\hline Ladies Finger & 4.00 & $2.20-3.62$ & 1.74 & - \\
\hline Brinjal & 1.20 & 1.62 & 1.24 & - \\
\hline Carrot & 4.10 & $1.90-4.90$ & -- & - \\
\hline Potato & 2.80 & $1.27-2.92$ & -- & - \\
\hline Onion & 3.70 & $1.00-3.00$ & -- & - \\
\hline Banana & 2.90 & $0.84-1.58$ & 0.84 & - \\
\hline Grapes & -- & $0.84-1.72$ & -- & - \\
\hline Mango & 3.70 & $0.80-1.80$ & -- & - \\
\hline Apple & 5.70 & $0.24-0.52$ & - & - \\
\hline Almond & 4.00 & -- & - & - \\
\hline Coconut & 4.40 & -- & -- & - \\
\hline Groundnut & 5.10 & -- & -- & - \\
\hline Tea(dry leaves) & -- & $39.80-68.59$ & - & - \\
\hline Tea infusion & -- & $11.13-37.34$ & -- & - \\
\hline Aerated drinks & -- & $0.77-1.44$ & -- & - \\
\hline Mutton & -- & $3.00-5.00$ & -- & - \\
\hline Beef & -- & $4.00-5.00$ & -- & - \\
\hline Fishes & 3.75 & -- & - & -- \\
\hline
\end{tabular}

Table3. Estimated total inorganic fluoride emission from majour industries in the United States [11]

\begin{tabular}{|l|l|}
\hline Sources & Emission Tons/Year \\
\hline Steel & 40100 \\
\hline Ceramics & 21200 \\
\hline Phosphet fertilizer and processsing Industry & 18700 \\
\hline Aluminium Industrv & 16000 \\
\hline Combustion of coal & 16000 \\
\hline Non Ferrous metal foundries & 4000 \\
\hline Welding operations & 27000 \\
\hline
\end{tabular}


R. Hema Krishna et al.

Table4. Summarized information on the occurrence of excessive fluoride in ground water in India [11]

\begin{tabular}{|l|l|l|l|}
\hline \multicolumn{1}{|c|}{ State } & \multicolumn{1}{|c|}{$\begin{array}{c}\text { No. of habitation with excess } \\
\text { fluoride }\end{array}$} & \multicolumn{1}{|c|}{ State } & \multicolumn{1}{c|}{$\begin{array}{c}\text { No. of habitation with excess } \\
\text { fluoride }\end{array}$} \\
\hline Andhra Pradesh & 7548 & Meghalaya & 33 \\
\hline Bihar & 12 & Maharashtra & 39 \\
\hline Gujrat & 2376 & Orrisa & 1138 \\
\hline Karnataka & 860 & Punjab & 700 \\
\hline Kerala & 287 & Rajasthan & 16560 \\
\hline Madhya Pradesh & 201 & Tamilnadu & 527 \\
\hline Haryana & 334 & Uttar Pradesh & 1072 \\
\hline Himachal Pradesh & 488 & West Bengal & 21 \\
\hline Delhi & 46 & & \\
\hline
\end{tabular}

Table5. Permissible limit of fluoride in drinking water prescribed by various organizations [11]

\begin{tabular}{|l|l|}
\hline \multicolumn{1}{|c|}{ Name of organization } & \multicolumn{1}{|c|}{$\begin{array}{c}\text { Permissible limit of fluoride ion } \\
\text { (mg/1) }\end{array}$} \\
\hline $\begin{array}{l}\text { World Health Organization } \\
\text { (International standard for drinking water) }\end{array}$ & 0.50 \\
\hline US Public Health Standard The committee on public health & 0.8. \\
\hline Engineering manual and code of practice, Government of India & 1.00 \\
\hline Indian Council of Medical Research recommendations & 1.00 \\
\hline ISI recommendations & 1.50 \\
\hline
\end{tabular}

Some effects of fluoride on the basis of their concentration are given in the below table 6

Table6. Effects of fluoride on the basis of their concentration

\begin{tabular}{|l|l|l|}
\hline \multicolumn{1}{|c|}{ Concentration of fluoride } & \multicolumn{1}{c|}{ Medium } & \multicolumn{1}{c|}{ Effects } \\
\hline $1 \mathrm{ppm}$ & Water & Water Dental caries reduction \\
\hline $2 \mathrm{ppm}$ or $<2 \mathrm{ppm}$ & Water & Mottled enamel(dental fluorosis) \\
\hline $8 \mathrm{ppm}$ & Water & $10 \%$ osteosclerosis \\
\hline $20-80 \mathrm{mg} / \mathrm{day}$ & Water or food & Water or food Crippling skeletal fluorosis \\
\hline $100 \mathrm{ppm}$ & Water or food & Thyroid changes \\
\hline $50 \mathrm{ppm}$ & Water or food & Growth retardation \\
\hline $125 \mathrm{ppm}$ & & Kidney changes \\
\hline $2.5-5.0 \mathrm{ppm}$ & Acute dose & Death \\
\hline
\end{tabular}

\section{Chemistry OF FLUORIDE}

Fluorine $\left(\mathrm{F}_{2}\right.$ or F-F) is element \#9 in the Periodic Table. The fluoride ion $\left(\mathrm{F}^{-}\right)$, which has one negative charge, must be accompanied by a cation such as sodium $(\mathrm{Na}+)$, as in sodium fluoride $(\mathrm{NaF}$ or $\mathrm{NaF})$. Other inorganics, such as liquid hydrofluoric acid (HF, often called hydrogen fluoride as a gas), hexafluorosilicic acid $\left(\mathrm{H}_{2} \mathrm{SiF}_{6}\right)$, and compounds with a P-F bond, such as the sodium mono fluoro phosphate $\left(\mathrm{Na}_{2} \mathrm{PO}_{3} \mathrm{~F}\right)$ used in toothpaste, as well as organics, such as methansulfonyl fluoride $\left(\mathrm{CH}_{3}\right.$ $\left.\mathrm{SO}_{2} \mathrm{~F}\right)$ and acetyl fluoride $\left(\mathrm{CH}_{3} \mathrm{COF}\right)$, also form $\mathrm{F}$ in water or alkali. The trifluoromethyl group $\left(\mathrm{CF}_{3^{-}}\right.$ ) or the fluoro phenyl group $\left(\mathrm{FC}_{6} \mathrm{H}_{4}-\right)$ are often incorporated into drug molecules to make them more resistant to being metabolized. Organic polymers (Teflon) and refrigerants with $-\mathrm{CF}_{2^{-}}-$groups are usually extremely stable both chemically and thermally. The fluoride content of the surface and the underground water is a function of many factors such as availability and solubility of parent fluoride minerals with which these water come in contact, rock porosity, velocity of flowing water, temperature of the interactions between the rocks and the water, $\mathrm{pH}$ of the water and concentration of calcium ions present in the water[12]. When a fluoride compound is dissolved in water, the element fluorine will be present mainly as fluoride ions. However, depending on the ionic concentrations and $\mathrm{pH}$ of the solutions the fluorides is also present in solution as $\mathrm{HF}_{2}$ and un dissociated HF. Now if it is assumed that the calcium fluoride is representative of the natural fluorides while sodium fluoride that of artificial fluoride, these compounds dissolve in water under the equivalent conditions such that they ionize as shown in the following equations.

Calcium fluoride:

$$
\begin{aligned}
& \mathrm{CaF}_{2} \rightleftharpoons \mathrm{Ca}^{++}+2 \mathrm{~F}^{-} \\
& \mathrm{F}-+\mathrm{H}+\stackrel{\longrightarrow}{\mathrm{HFF}}+\mathrm{F}+\longrightarrow \mathrm{HF}^{2-}
\end{aligned}
$$


Sodium fluoride:

$$
\begin{aligned}
& \mathrm{NaF} \longrightarrow \mathrm{Na}++\mathrm{F}- \\
& \mathrm{F}-+\mathrm{H}+\longrightarrow \mathrm{HF} \\
& \mathrm{HF}+\mathrm{F}-\longrightarrow \mathrm{HF}_{2}
\end{aligned}
$$

In both these instances, fluoride is yielded as F-, HFand HF2 and these will be chemically and physiologically indentical with their equivalentsirrespective of the two compounds they are deliveredfrom.

Excess fluoride may lead to an increased demineralization leading to the precipitation of Calcium phosphate and Calcium fluoride and it interferes with calcium metabolism. Thus excess fluoride intake can initiate an erratic Calcium metabolism which results in deformed bones and mottling of teeth. Prolong ingestion of fluoride into the body system above the recommended level leads to a dreaded, crippling disease called Fluorosis which include dental and skeletal fluorosis apart from thyroid problems, growth retardation, kidney damage, heart attacks etc. In fluorosis, due to the substitution of active $\mathrm{OH}$ - group by $\mathrm{F}$ - some enzymes like enolose, pyrophosphatase become inactive [13-14]. Fluoride concentration greater than $3 \mathrm{ppm}$ in drinking water may cause dental fluorosis (indicated by weakening of tooth enamel, development of brown or yellow patches on the teeth). Intake of fluoride above 20ppm may lead to severe toxicity like osteosclerosis(in which $50 \%$ of the $\mathrm{OH}$ - group in $\left[\mathrm{Ca}_{5}\left(\mathrm{PO}_{4}\right)_{3}(\mathrm{OH})\right]$ is replaced by $\mathrm{F}$ - in bones). It leads to skeletal fluorosis and hyper calcification. Consequently the bones of limbs joints, pelvis, and spine are severely damaged. In fluorosis even the ligaments of spine and collagen of bones are calcified and the patients are crippled due to stiff joints $[15,16,17]$.

Bones are largely composed of $\mathrm{Ca}$ compounds, particularly carbonated hydroxyapatite $\left(\mathrm{Ca}_{10}\left(\mathrm{PO}_{4}\right)_{6}(\mathrm{OH})_{2}\right)$ or $\mathrm{Ca}_{5}\left(\mathrm{PO}_{4}\right)_{3}(\mathrm{OH})$.When reacted with HF it forms an insoluble salt, $\mathrm{CaF} 2$. This insoluble salt, $\mathrm{CaF} 2$ is cleared by the body through excretion and as a consequence some of the calcium that would have been part of the bone matrix is washed away. This causes increased bone density with decreased bone strength [18].

\section{Dimineralision Process}

$$
\begin{aligned}
& \mathrm{Ca}_{5}(\mathrm{PO4})_{3}(\mathrm{OH})+\mathrm{HF} \longrightarrow \mathrm{Ca}_{5}(\mathrm{PO4})_{3} \mathrm{~F}+\mathrm{H}_{2} \mathrm{O} \\
& \mathrm{Ca}_{5}\left(\mathrm{PO}_{4}\right)_{3} \mathrm{~F} \longrightarrow 2 \mathrm{Ca}_{3}\left(\mathrm{PO}_{4}\right)_{2}+\mathrm{CaF}_{2}
\end{aligned}
$$

Fluoride poisoning can be treated by the administration of soluble Calcium salt such as gluconate or chloride to produce insoluble $\mathrm{CaF} 2$ and to reverse the demineralization process.

\section{Mineralisation Process}

$$
\begin{aligned}
& 3 \mathrm{Ca}_{2}++2 \mathrm{PO}_{4}{ }^{3-} \longrightarrow \mathrm{Ca}_{3}(\mathrm{PO} 4)_{2} \\
& 3 \mathrm{Ca}_{3}(\mathrm{PO4}) 2+\mathrm{CaF}_{2} \stackrel{\longrightarrow}{\longrightarrow} \mathrm{Ca}_{5}(\mathrm{PO})_{3} \mathrm{~F}
\end{aligned}
$$

Some governments are not yet fully aware of the fluoride problem or convinced of its adverse impact on their populations. Efforts are therefore needed to support more research on the subject and promote systematic policy responses by governments. The absence of public programs for prophylaxis of the dental caries brings about a chaotic intake of fluorine of different origin, with no control on the part of competent and knowledgeable personnel. As a result in numerous regions and settlements the cases of fluorosis with different degrees of seriousness have become more frequent in recent years. Part of these cases brings only about a cosmetic defect, while others represent a serious medical problem requiring medical treatment [19]. There are three types of fluorosis, 1. Dental fluorosis, 2. Skeletal fluorosis, Non skeletal fluorosis.

\section{Dental Fluorosis}

Dental fluorosis is the result of chronic endogenic intake of fluorides in amounts exceeding the optimal daily dose of $1 \mathrm{ppm}$. It is a developmental disturbance of dental enamel, caused by successive exposures to high concentrations of fluoride during tooth development, leading to enamel with lower mineral content and increased porosity. The severity of dental fluorosis depends on when and for how long the overexposure to fluoride occurs, the individual response, weight, degree of physical activity, nutritional factors and bone growth. The risk period for esthetic changes in permanent teeth is between 20 and 30 months of age [20]. The recommended level for daily fluoride intake is $0.05-0.07 \mathrm{mg} \mathrm{F} / \mathrm{Kg} / \mathrm{day}$, which is considered of great help in preventing dental caries, acting in remineralisation. 


\section{R. Hema Krishna et al.}

Depending on the quantity of the intake different degrees of changes in the enamel are observed. These changes can be slight, namely involving the emergence of white lines or stains on the enamel, the lines in question being vertical or horizontal. The medium degree of changes involves yellow to brown stains, the hard degree of changes involving an overall affection of the enamel with chalkwhite stains, as well as with numerous dark-coloured stains and enamel losses. The microscopic changes come down to a disturbed mineralisation of the enamel, the process involving different degrees of increased porosity of the subsurface layers .Dental fluorosis is observed in regions with excessive occurrence of fluorine in the drinking water or is the result of overdoses of fluorine within an endogenic fluorine prophylaxis. In India different Food items with high content of fluorine are on the market. For instance the Rock salts, Canned fish and meat, Packed food items like fruit juice, Black tea (tea without milk), Tea with lemon, Food items with kalanamak (black salt), Pan Masala and tobacco [21-22].

Historically, it was believed that fluoride needed to become incorporated into the crystal lattice of enamel in order to effectively prevent the development of dental caries. Fluoride was considered to improve lattice stability and render the enamel less soluble to acid demineralization. Since the incorporation of fluoride into enamel, as partially fluoridated hydroxyapatite, was believed to be essential for its action, fluoride was thought best ingested. There is now, however, an increasing body of evidence to suggest that a substantial part of the cariostatic activity of fluoride is due to its effects on erupted teeth, and that the continual presence of fluoride in the saliva and in the fluid phase of dental plaque is critical to its mechanism of action. There is a growing consensus that through its interaction with the surface of enamel, fluoride in saliva and dental plaque inhibits the demineralization and promotes the remineralization taking place at the surface of the tooth $[23,24,25]$.

Fluoride is the most important caries-preventive agent in dentistry. In the last two decades, increasing fluoride exposure in various forms and vehicles is most likely the explanation for an increase in the prevalence of mild-to-moderate forms of dental fluorosis in many communities, not the least in those in which controlled water fluoridation has been established. The effects of fluoride on enamel formation causing dental fluorosis in man are cumulative, rather than requiring a specific threshold dose, depending on the total fluoride intake from all sources and the duration of fluoride exposure. Enamel mineralization is highly sensitive to free fluoride ions, which uniquely promote the hydrolysis of acidic precursors such as octa calcium phosphate and precipitation of fluoridated apatite crystals. Once fluoride is incorporated into enamel crystals, the ion likely affects the subsequent mineralization process by reducing the solubility of the mineral and thereby modulating the ionic composition in the fluid surrounding the mineral [26].

Currently, there is no direct proof that fluoride at micromolar levels affects proliferation and differentiation of enamel organ cells. Fluoride does not seem to affect the production and secretion of enamel matrix proteins and proteases within the dose range causing dental fluorosis in man. Most likely, the fluoride uptake interferes, indirectly, with the protease activities by decreasing free $\mathrm{Ca}^{2+}$ concentration in the mineralizing milieu. The $\mathrm{Ca}^{2+}$-mediated regulation of protease activities is consistent with the in situ observations that (a) enzymatic cleavages of the amelogenins take place only at slow rates through the secretory phase with the limited calcium transport and that, (b) under normal amelogenesis, the amelogenin degradation appears to be accelerated during the transitional and early maturation stages with the increased calcium transport [27].

Since the 1930s, dentists have rated the severity of fluorosis using the following categories were observed in figure $2: 1$. Questionable. Slight defects of the translucent normal dental enamel ranging from several white tiny specks to occasional white stains. 2. Very mild. Tiny non-transparent white specks scattered randomly and irregularly upon the tooth surface and covering less than $25 \%$ of the tooth surface. 3. Mild. Areas with white stains on the enamel covering from 25 to $50 \%$ of the tooth surface 4. Moderate. The tooth surface is prone to the marked erasure with frequent brown stains of irregular shape. 5. Severe. All tooth enamel surfaces are affected. Extremely marked hypoplasia that can change the entire tooth form. Isolated or confluent pits are the most basic diagnostic sign of this code. Brown stains occur frequently. One can get an impression that a tooth is attacked by the corrosion [28-29]. 

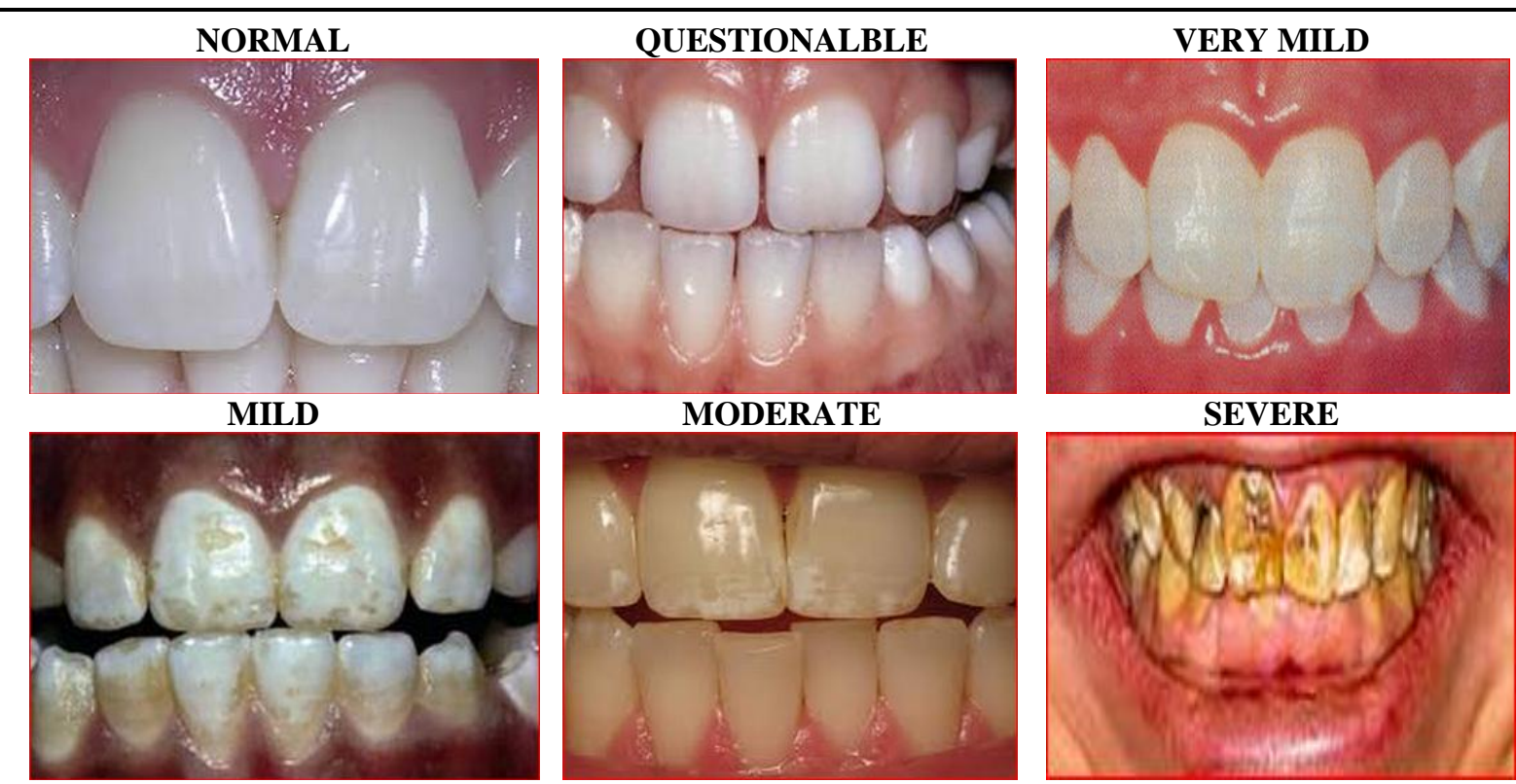

Figure2. Classification of the dental fluorosis

Dental fluorosis and skeletal fluorosis can be very independent because dental fluorosis occurs only when one is exposed during childhood when the permanent teeth are being formed, once dental fluorosis develops, it is permanent and leaves past historical drinking water fluoride level evident clinically all throughout the life. Dental fluorosis seen in adult thus is only a „tell-tale sign of consumption of drinking water in childhood which had high fluoride content. On the other hand, the exposure to high fluoride level during adulthood leads to development of skeletal and non-skeletal fluorosis but never dental fluorosis[30].

\section{Skeletal Fluorosis}

Skeletal fluorosis is at endemic levels in at least 25 countries around the world. In the two countries where it is most prevalent - China and India - it affects 2.7 million and 6 million people respectively. It is a debilitating disease, especially in latter stages. While in the beginning, the achy joints and stiffness may resemble arthritis, advanced fluorosis causes severe deformities as the ligaments of the neck and vertebrae calcify (harden), muscle tissue wastes away, and movement becomes more and more limited [31-32].

Scientific surveys indicate that any water supply containing more than $1 \mathrm{ppm}$ of fluoride to be a risk for skeletal fluorosis. Based on a large body of animal and human research, it is now known that fluoride ingestion can reduce bone strength and increase the rate of fracture. There are several plausible mechanisms by which fluoride can reduce bone strength. As discussed below, these mechanisms include:

1. Reduction in Cortical Bone Density

2. De-bonding of Mineral-Collagen interface

3. Damage to Collagen

4. "Hypo-mineralization" (Increase in Unmineralized Osteoid)

5. "Hyper-mineralization" (Brittle Bone)

6. Non-Uniformity of Mineralization

7. Osteocyte Damage

While the relative importance of these mechanisms may depend on dose, age, and nutritional, it has been shown that fluoride can reduce bone strength prior to the onset skeletal fluorosis. Thus, at least some, if not all, of these mechanisms can operate before detectable signs of skeletal fluorosis are present.

Prolonged, excessive exposure to fluoride can cause a debilitating bone disease known as skeletal fluorosis. The disease develops insidiously and can be difficult to distinguish from a number of other 


\section{R. Hema Krishna et al.}

bone and joint diseases. Research shows that individual susceptibility to fluorosis varies greatly across the population, both with respect to the doses and duration of exposure that can cause the disease, and the skeletal manifestations and symptoms that result [33].

In the initial stages, known as "pre-skeletal" fluorosis, a patient may suffer a variety of symptoms in the absence of any detectable bone changes, including joint pains, joint stiffness, and gastric distress. The absence of bone changes makes this pre-skeletal phase difficult to diagnose, because the symptoms are indistinguishable from common forms of arthritis, such as osteoarthritis and rheumatoid arthritis. Even when bone changes do develop, correct diagnosis can remain elusive. This is because the bone changes in skeletal fluorosis mimic the bone changes in other diseases, including osteoarthritis, renal osteodystrophy, spondylosis, DISH, Paget's Disease, and osteopetrosis [34].

The first ever report of endemic skeletal fluorosis was from Podili, Darsi and Kanigiri areas of Prakasam district in Andhra Pradesh, a province in south India, in the year 1937. This report also had the description of neurological manifestations of fluorosis, a manifestation of late stage of fluoride toxicity. Surprisingly, the fluoride levels of drinking water in these areas were not very high and were in the range of 1-3 PPM and rarely exceeded 6 PPM [35] . Development of skeletal fluorosis has not been reported with such levels of fluoride in drinking water from other parts of the world. The proposed possible mechanisms for such severe manifestations by the authors included: (a) high atmospheric temperatures $\left(115-116^{\circ} \mathrm{F}\right)$ during summer months; (b) hard physical labor activity (both factors are likely to lead to high water intake); (c) poor nutrition, deficient in calories and also vitamin C. What was not realized then was that the ten patients reported on impaired renal functions [36] .It is now established that diseased kidneys cannot handle fluoride excretion leading to fluoride toxicity and development of skeletal fluorosis even while consuming low levels of fluoride in drinking water supplies. Recent studies also suggest that the presence of certain trace elements like strontium, silica, uranium, calcium, magnesium etc., in high concentration in water and food could influence fluoride toxicity, some beneficial and others detrimental. The above observations suggest that the factors that may predispose to the development of endemic skeletal fluorosis include: (a) high fluoride intake through water and food; (b) continued exposure to fluoride; (c) strenuous manual physical activity; (d) poor nutrition; (e) impaired renal function and (f) abnormal concentrations of certain trace elements [37].

\section{Symptoms of SKeletal Fluorosis}

Skeletal fluorosis, a complicated illness caused by the accumulation of too much fluoride in the bones, has a number of stages. The first two stages are preclinical-that is, the patient feels no symptoms but changes have taken place in the body. In the first preclinical stage, biochemical abnormalities occur in the blood and in bone composition; in the second, histological changes can be observed in the bone in biopsies. Some experts call these changes harmful because they are precursors of more serious conditions. Others say they are harmless.

In the early clinical stage of skeletal fluorosis, symptoms include pains in the bones and joints; sensations of burning, pricking, and tingling in the limbs; muscle weakness; chronic fatigue; and gastrointestinal disorders and reduced appetite. During this phase, changes in the pelvis and spinal column can be detected on x-rays. The bone has both a more prominent and more blurred structure.

In the second clinical stage, pains in the bones become constant and some of the ligaments begin to calcify. Osteoporosis may occur in the long bones, and early symptoms of osteosclerosis (a condition in which the bones become more dense and have abnormal crystalline structure) are present. Bony spurs may also appear on the limb bones, especially around the knee, the elbow, and on the surface of tibia and ulna.

In advanced skeletal fluorosis, called crippling skeletal fluorosis, the extremities become weak and moving the joints is difficult. The vertebrae partially fuse together, crippling the patient Inner nd outer images of Skeletal Fluorosis was observed in figure 3.

Most experts in skeletal fluorosis agree that ingestion of $20 \mathrm{mg}$ of fluoride a day for 20 years or more can cause crippling skeletal fluorosis. Doses as low as 2 to $5 \mathrm{mg}$ per day can cause the preclinical and earlier clinical stages.

The situation is complicated because the risk of skeletal fluorosis depends on more than the level of fluoride in the water. It also depends on nutritional status, intake of vitamin D and protein, absolute amount of calcium and ratio of calcium to magnesium in drinking water, and other factors. 
In parts of India, China, Africa, Japan, and the Middle Fast, large numbers of people have skeletal fluorosis from drinking naturally fluoridated water. In India about a million people have this disease. Most of the victims live in areas where the water fluoride level is $2 \mathrm{ppm}$ or above, but some cases are found in communities with natural fluoride levels below 1 ppm [38-40] .

\section{Symptoms of Skeletal Fluorosis Phases}

\begin{tabular}{|l|l|}
\hline Osteosclerotic phase & \multicolumn{1}{c|}{ Symptoms and signs } \\
\hline Normal Bone & Normal \\
\hline Preclinical Phase & Asymptomatic; slight radio graphically-detectable increases in bone mass \\
\hline Clinical Phase I & Sporadic pain; stiffness of joints; osteosclerosis of pelvis and vertebral spine \\
\hline Clinical Phase II & $\begin{array}{l}\text { Chronic joint pain; arthritic symptoms; slight calcification of ligaments' increased } \\
\text { osteosclerosis and cancellous bones; with/without osteoporosis of long bones }\end{array}$ \\
\hline $\begin{array}{l}\text { Phase III: Crippling } \\
\text { Fluorosis }\end{array}$ & $\begin{array}{l}\text { Limitation of joint movement; calcification of ligaments of neck vertebral column; } \\
\text { crippling deformities of the spine and major joints; muscle wasting; neurological } \\
\text { defects/compression of spinal cord }\end{array}$ \\
\hline
\end{tabular}

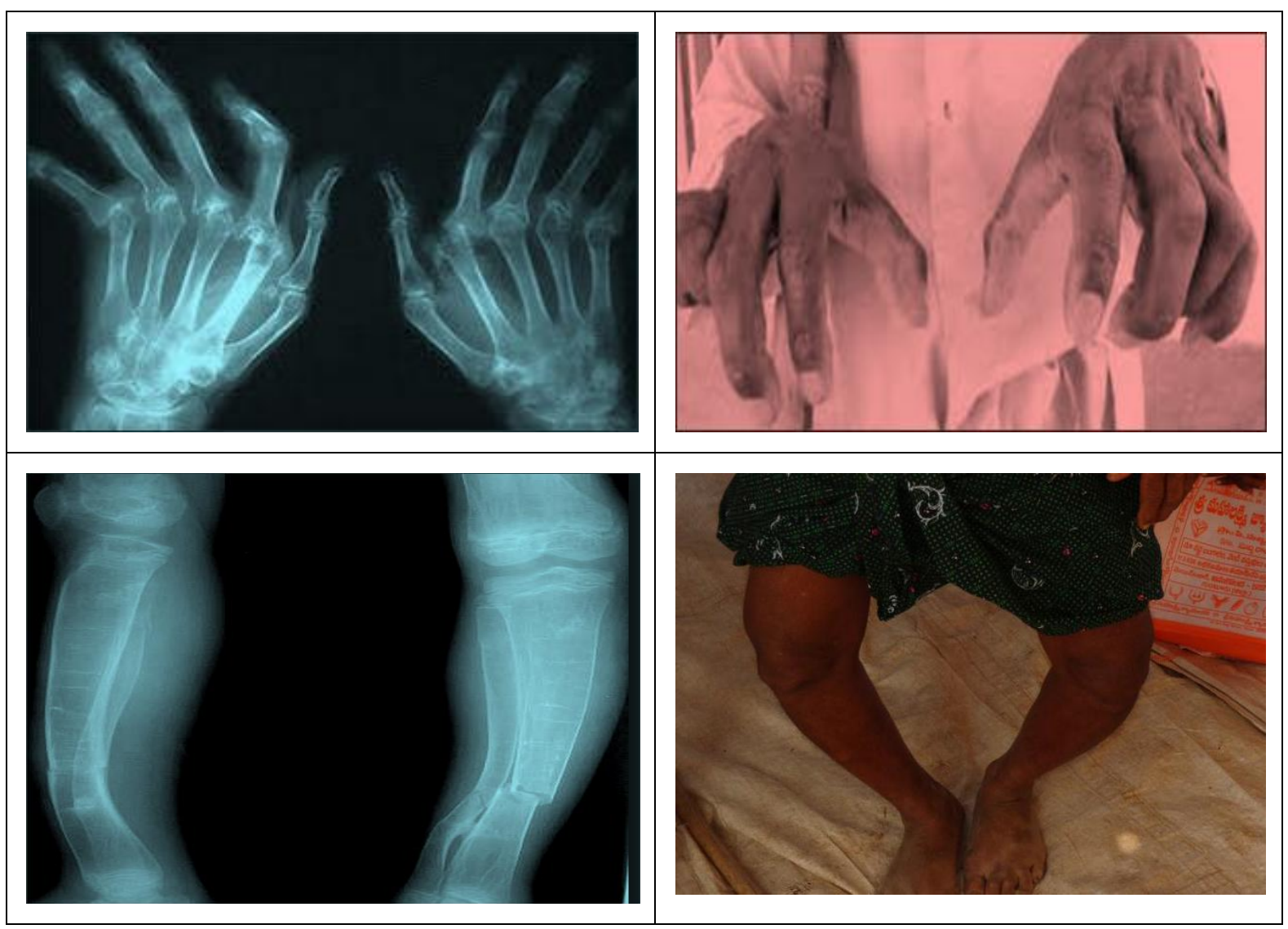

Figure3. Inner and outer images of Skeletal Fluorosis

\section{NON - SKelEtal FluOROSIS}

The conventional belief that fluoride affects only bone and tooth has been negated in recent years as the evidences on the involvement of the soft tissues/organs/systems of the body are convincing. Investigations have demonstrated that there is involvement of soft tissues like skeletal muscles, red blood cells, gastro-intestinal mucosa, ligaments, spermatozoa and thyroid gland in human fluorosed patients. There are evidences on involvement of other organ and systems of animal models viz. kidney, liver, adrenal gland and reproductive organ. On-ulcer dyspeptic complaint is the earliest manifestation of fluoride poisoning. Hence, it is possible to diagnose fluoride poisoning at early stages [41-43].

This kind of fluorosis is often over looked because of the wrong prevailing notion that fluoride affects only bone and teeth. In this context, the words of the American University Chemistry Professor Dr.William Hitzy is worth mentioning wherein he says that —it would be a biological miracle if fluoride did not cause other harm prior to producing the end stage form of toxicity like dental 


\section{R. Hema Krishna et al.}

fluorosis ans skeletal fluorosisl. It is found that fluoride can cause arthritic symptoms and bone fracture well before the appearance of the dreaded fluorosis and it affects many other soft tissues like the kidney, the brain, the pineal gland, the thyroid gland, the arteries, the cardio vascular system, the reproductive system etc other than the teeth and bone. Attempts have been made to highlight the recent advances in the field of non-skeletal fluorosis research [44]. This kind of fluorosis is often overlooked due to misconception that fluoride affects only bone and teeth. Fluoride when consumed in excess can cause several other kinds of manifestations;

\subsection{Neurological}

Nervousness, depression, tingling sensation of fingers and toes, excessive thirst and tendency to urinate more frequently

\subsection{Muscular}

Muscle weakness, stiffness, pain in muscles and loss of muscle power

\subsection{Risk of Fluorosis: What Do we Know and How to Minimize it?}

Today, there is clear evidence that fluorosis is increasing worldwide. This concern raises doubts about the beneficial aspects of systemic fluoride methods. But there are clear evidences that these methods have more beneficial effects than risks. For instance, in spite of the potential risk for dental fluorosis, dietary fluoride supplements are regarded as effective in preventing caries and are still available in several countries. This method was not discussed in this paper but this issue is also relevant [45] The recent reduction in fluoride levels in the water communities cannot be interpreted as a limitation of the method.

Conversely, this adjustment proves that water fluoridation is still necessary. So, what we know about the risk of dental fluorosis? First, the issue is not as simple as it was before (when water fluoridation started), since today it can involve several sources of fluoride. Second, an 'optimal' dose is a theoretical value, maybe we should work with range of risk and range of concentrations in systemic methods. Third, the classification of systemic x topical methods is no longer valid and might be changed. These major categories might be better classified as: professional methods (varnishes, gels) community methods (salt, water, milk) and individual methods (toothpastes, mouthrinses and supplements). Considering these categories, operational strategies can be more straightforward on the basis of those who are in charge of the method: the dentist, the health authority or the patient.

Other point of concern is that some degree of enamel fluorosis is inevitable with water fluoridation. However, most cases of dental fluorosis are of mild severity. Future studies about fluorosis perception will be valuable for evaluating the level of concern of the population about dental fluorosis. Dean regarded an increased prevalence of fluorosis as an acceptable risk when compared to the preventive benefits.

There are good strategies to minimize the risk of dental fluorosis. The first step is to get the information about the methods of delivering fluoride in a region or town (including toothpastes). Thus, investigating the possible sources of fluoride on an individual basis as well as in a communal basis is important. The risk of developing fluorosis shows a different trend on urban and rural communities. It is a more common cause of fluorosis on rural communities the high content of fluoride on the drinking water, such as groundwater. On the contrary it is more common on urban communities the development of fluorosis due to the irrational use of toothpaste by children under 6 years old [46-47] The emerging concern about dental fluorosis must be evaluated in the perspective that systemic methods were already operating when other sources of fluoride were introduced. Thus, the effectiveness of fluoride is not the same for all methods since caries burden is lowering off. It is true that a reclassification to substitute the traditional systemic versus topical methods is necessary. What is not necessary is to simply oppose systemic fluoride methods as long as caries is still the most prevalent disease in many parts of the world.

\section{Concluding Remarks}

- Know the level of fluoride in your drinking water. If your drinking water comes from a public source, you can find out about the levels of fluoride in your drinking water by contacting your local community water system. People who get their drinking water from a private source such as a well can have the fluoride levels tested by a reputable laboratory 
- People who live in areas with high levels of fluoride in the water might consider using alternate sources of drinking water, such as bottled water. Most bottled water has some fluoride, with natural spring waters tending to have the least. You can contact the bottler to find out about fluoride levels. There are also several methods to filter fluoride out of water, although these can be expensive.

- Most studies support the view that the caries-preventive effect of fluoride is mainly post-eruptive. This evidence must not be interpreted as a true limitation of systemic fluoride methods since a topical effect will take place when someone is ingesting fluoride in water, milk or salt or taking a fluoride lozenge.

- Dietary F intake must be considered before any systemic method of fluoridation is implemented. Hence, it is very important to monitor the total fluoride intake of children in the first 3 years of life in order to avoid undesirable aesthetically fluorosis, particularly in central incisors.

- Most systemic methods available are of low cost showing a good cost-benefit relation.

- The overlapping of systemic methods of delivering fluoride must be avoided in order to control caries without the risk of developing dental fluorosis.

- Dental fluorosis related to systemic fluoride methods are of minor concern since mild dental fluorosis is the majority of the cases observed from clinical and epidemiological observations.

- Reclassification to substitute the traditional 'systemic' versus 'topical' methods is necessary. The major categories might be classified as : professional methods (varnishes, gels) community methods (salt, water, milk) and individual methods (toothpastes, mouth rinse and supplements)

\section{ACKNOWLEDGEMENT}

The authors are thankful to the authorities of the Acharya Nagarjuna University, Andhrapradesh, India and Department of Chemistry, University of Toronto Canada for providing us Technical and library facilities to complete this manuscript.

\section{REFERENCES}

[1] Yadav J P, Lata S. Kataria S K., Kumar S. Fluoride distribution in ground water and survey of dental fluorosis among school children in the villages of the Jhajjar District, Haryana, India. Enviorn Geochem Health 2009:31(4);431-8.

[2] Singh A, Vazirani S J Jolly S S, Bansal B C, Mathur O C. Endemic Fluorosis: with particular reference to dental and systemic intoxication. Postgrad. Med J. 1962, 38:150-6.

[3] Gupta SK, Gupta RC, Gupta AB.Is there a need of extra fluoride in children? Indian Pediatr 2009.46(9): 755-9

[4] V. Subhashini, A.V.V.S.Swamy, Z. Vishnuvardhan, P. Brahmaji rao, k. Sasidhar and R. Hema krishna Investigation on defluoridation from the aqueous Solutions using a mixture Alum and Lime, International journal of applied Environmental sciences, 2012,7(4) ,pp 453-464.

[5] V.Subhashinia A. V. V. S. Swamy and R. Hema krishna, Deflouridation from aqueous Solutions using Alum,Journal of Chemical Science Transactions,2012.1(3), 552-559, DOI:10.7598/cst2012.206

[6] Rani, Bina, Fluoride and fluorosis in Rajasthan: An Overview, A project Report [IGNOU], 2006

[7] Anurag Tewari ,Ashutosh Dubey Defluoridation of Drinking Water: Efficacy and Need Journal of Chemical and Pharmaceutical Research 2009, 1 (1):31-37.

[8] Salah H, Arab N. Application of PIGE to determine fluorine concentration in human teeth: Contribution to fluorosis study. J Nucl Radiochem Sci 2007; 8: 31-4.

[9] Saravanan S, Kalyani C, Vijayarani M, Jayakodi P, Felix A, Nagarajan S, Arunmozhi P, Krishnan V. Prevalence of dental fluorosis among primary school children in rural areas of Chidambaram Taluk, Cuddalore District, Tamil Nadu, India. Indian J Commun Med.2008.33: 146-50.

[10] Srivastava AK, Singh A, Yadav S, Mathur A. Endemic Dental and Skeletal Fluorosis: Effects of High Ground Water Fluoride in some North Indian Villages. International Journal of Oral \& Maxillofacial Pathology. 2011: 2(2): 7-12. 
[11] Disorders of Mineral Metabolism: Trace Minerals, Felix Bronner, Jack W. Coburn - Health \& Fitness - 2014 - 516 pages

[12] Arlappa N, Aatif Qureshi I, Srinivas R. Fluorosis in India: an overview. Int J Res Dev Health. April 2013; Vol 1(2)

[13] Rawlani S, Rawlani S, Rawlani S. Assessment of skeletal and non-skeletal fluorosis in endemic fluoridated areas of Vidharbha Region, India: A survey. Indian J Community Med 2010; 35: 298-301.

[14] Oncu M, Gulle K, Karaoz E, Gultekin F, Karaoz S, Karakoyun I, Mumcu E. Effect of chronic fluorosis on lipid peroxidation and histology of lung tissues in first and second generation rats. Toxicol Ind Health. 2006 Oct; 22(9): 375-80.

[15] Susheela AK. Fluorosis: Indian scenario: A treatise on fluorosis. Fluorosis Research and Rural Development Foundation; New Delhi, India. 2001

[16] Yadav Ashok Kumar, Khan Parveen and Saxena Umesh (2009). Geochemical Observation of

[17] Fluoride In Ground Water of Tonk (Rajasthan). Rasayan Journal of Chemistry 2(4) 994-1000.

[18] Agency for Toxic Substances and Disease Registry. 2003. Toxicological Profile for Fluorides, Hydrogen Fluoride, and Fluorine (Update). Available: http://www.atsdr.cdc.gov/toxprofiles/tp11.pdf [accessed 5 April 2010].

[19] Chen YX, Han F, Zhou Z, Zhang H, Jiao X, Zhang S, et al. 1991. Research on the intellectual development of children in high fluoride areas. Chin J Control Endem Dis 6(suppl):99-100. Available: http://www.fluoridealert.org/chinese/ [accessed 20 August 2012].

[20] China News. 2008. Twenty-eight provinces were affected by fluorosis in China [in Chinese]. Available: http://news.qq.com/a/20081216/001707.htm [accessed 3 July 2012].

[21] Guo XC, Wang R, Cheng C, Wei W, Tang L, Wang Q, et al. 1991. A preliminary exploration of IQ of 7-13 year old pupils in a fluorosis area with contamination from burning coal. Chin $\mathrm{J}$ Endemiol 10:98-100. Available: http://www.fluoridealert.org/chinese/ [accessed 20 August 2012].

[22] Li XH, Hou GQ, Yu B, Yuan CS, Liu Y, Zhang L, et al. 2010. Investigation and analysis of children's intelligence and dental fluorosis in high fluoride area [in Chinese]. J Med Pest Control 26(3):230-231.

[23] U.S. EPA. 2011. EPA and HHS Announce New Scientific Assessments and Actions on Fluoride: Agencies Working Together to Maintain Benefits of Preventing Tooth Decay while Preventing Excessive,Exposure.Available:http://yosemite.epa.gov/opa/admpress.nsf/bd4379a92ceceeac8525 735900400c27/86964af577c37ab285257811005a8417!OpenDocument [accessed 7 January 2011].

[24] Zhang M, Wang A, Xia T, He P. 2008. Effects of fluoride on DNA damage, S-phase cell-cycle arrest and the expression of NF- $\mathrm{\kappa B}$ in primary cultured rat hippocampal neurons. Toxicol Lett 179:1-5.

[25] Wang SH, Wang LF, Hu PY, Guo SW, Law SH. 2001. Effects of high iodine and high fluorine on children's intelligence and thyroid function [in Chinese]. Chin J Endemiol 20(4):288-290.

[26] Wang SX, Wang ZH, Cheng XT, Li J, Sang ZP, Zhang XD, et al. 2007. Arsenic and fluoride exposure in drinking water: children's IQ and growth in Shanyin County, Shanxi Province, China. Environ Health Perspect 115:643-647.

[27] Wang ZH, Wang SX, Zhang XD, Li J, Zheng XT, Hu CM, et al. 2006. Investigation of children's growth and development under long-term fluoride exposure [in Chinese; abstract in English]. Chin J Control Endem Dis 21(4):239-241.

[28] S. L. Choubisa., Proc Natl Acad Sci. India Sect B Bio Sci., 2013, 83(3), 317-321.

[29] C. Murutu, M.S. Onyango, A. Ochieng, and F.A. Otieno., Water SA.,2012,38 (2), 279-286.

[30] Yadav Ashok Kumar, Khan Parveen and Saxena Umesh (2009). Geochemical Observation of Fluoride In Ground Water of Tonk (Rajasthan). Rasayan Journal of Chemistry 2(4) 994-1000.

[31] Choubisa SL. Endemic fluorosis inSouthern Rajasthan, India. Fluoride 2001;34(1):61-70.

[32] Bhatnagar, A., Kumar, E. and Sillanpää, M., 2011, Fluoride removal from water by adsorption A review, Chem. Eng. J., 171, 811-840. 
[33] Pinon-Miramontes, M., Bautista-Margulis, R.G. and Perez-Hernadez, A., 2003, Removal of arsenic and fluoride from drinking water with cake alum and a polymeric anionic flocculent., Fluoride, 36, 122-128.

[34] Xu, X., Li, Q., Hao, C., Pang, J., Sun, L., Hao, A. and Zhai, J., 2011, Adsorption of fluoride from aqueous solution on magnesia-loaded fly ash cenospheres., Desalination, 272, 233-239.

[35] Ramdani, A., Taleb, R., Benghalem, A. and Ghaffour, N., 2010, Removal of excess fluoride ions from Saharan brackish water by adsorption on natural materials, Desalination, 250, 408-413.

[36] Yadav, A.K., Kaushik, C.P., Haritash, A.K., Kansal, A. and Rani, N., 2006, Defluoridation of groundwater using brick powder as an adsorbent., J. Hazardous Mater., 128, 289-293.

[37] Paya, P. and Bhatt, S.A., 2010, Fluoride contamination in groundwater of Patan District, Gujarat, India., International Journal of Engineering Studies, 2 (2), 171-177.

[38] Mahapatra M.K., Mishra A. and Das B.P., 2005, Fluorosis first reported in Naupada district of Orissa India., Ecology Environment and Conservation, 11(2), 277-280.

[39] Borah, L. and Dey, N.C., 2009, Removal of fluoride from low TDS water using low grade coal., Indian J. Chem. Technol., 16, 361-363.

[40] Murutu, C., Onyango, M.S., Ochieng, A. and Otieno, F.A., 2012, Fluoride removal performance of phosphoric acid treated lime: Breakthrough analysis and point-of-use system performance., Water SA, 38 (2), 279-286.

[41] Warnakulasuriya, S., Harris, C., Gelbier, S., Keating, J. and Peters, T., 2002, Fluoride content of alcoholic beverages., Clin. Chim. Acta., 320 (1-2), 1-4.

[42] Behrendt, A., Oberste, V. and Wetzel, W.E., 2002, Fluoride concentration and pH of iced tea products., Caries Res., 36, 405-410.

[43] WHO (World Health Organization), 2006, Guidelines for Drinking-Water Quality: Incorporating First Addendum toThird Edition., World Health Organization, Geneva., 375 p.

[44] Jha, S. K., Nayak, A. K., Sharma, Y. K., Mishra, V. K., \& Sharma, D. K. (2008). Fluoride accumulation in soil and vegetation in the vicinity of brick fields. Bulletin of Environmental contamination and Toxicology,80, 369-373.

[45] Abanto Alvarez J, Rezende KM, Marocho SM, Alves FB, Celiberti P, Ciamponi AL Dental fluorosis: exposure, prevention and management. Med Oral Patol Oral Cir Bucal. 2009; 14:E103-7.

[46] Sarvaiya BU, Bhayya D, Arora R, Mehta DN. Prevalence of dental fluorosis in relation with different fluoride levels in drinking water among school going children in Sarada tehsil of Udaipur district, Rajasthan. J Indian Soc Pedod Prev Dent. 2012;30:317-22.

[47] Firempong C, Nsiah K, Awunyo-Vitor D, Dongsogo J. Soluble fluoride levels in drinking watera major risk factor of dental fluorosis among children in Bongo community of Ghana. Ghana Med J. 2013;47:16-23

[48] Whitford GM (1994). "Intake and Metabolism of Fluoride". Advances in Dental Research 8 (1): $5-14$.

\section{Authors' Biography}

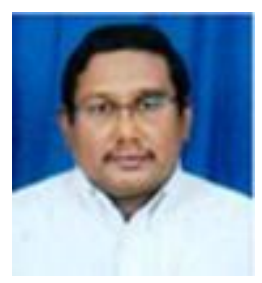

Dr. A.V.V.S. Swamy, M.Sc., Ph.D., D.E.Sc., is the Coordinator of the Department of Environmental Sciences, Acharya Nagarjuna University, Guntur, A.P, India. So far published more than 70 publications in various reputed National and International Journals. Four Ph.D.s and Six M.Phil. Degrees are awarded under his guidance. He is also a Member of CFO Committee, A.P. State Pollution Control Board, Andhra Pradesh. Delivered a number of Radio talks in All India Radio. Organised Workshops to Lecturers, professionals and students. Organised two National Seminars and also contributes articles on Environmental Importance in Regional Language (Telugu). Contributed chapters in edited volumes. Prepared Study Material for Environmental Studies for the Centre for Distance Education, Acharya Nagarjuna University. Areas of specialisation are Ecology, Wildlife Conservation, Phytoremediation, Air Pollution Impacts, EIA and adsorption techniques. 


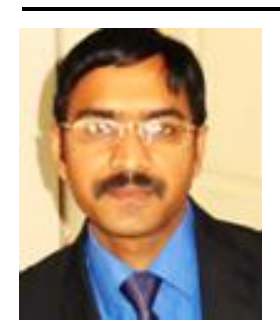

Dr. Hema Krishna Ravuri, has obtained his MSc, MPhil, PhD and PDF degrees from reputed universities in India and Canada. He has more than fourteen years of excellent teaching, research and administration experience at undergraduate, graduate and post graduate levels in three different continents (Asia, Africa and North America). He has presented his research works in various seminars, conferences and he has so for published thirty five research articles in national and international scientific journals. He has been working as reviewer and editorial board member of various international scientific journals. He has delivered twenty five National and International Guest Lectures. Areas of specialisation are Bio-Hydrogen, Adsorption of Heavy metals, Removal of Fluorides. Phytoremediation of Heavy metals, Air pollution, Solid Waste Management, Chemistry of mangrove plants and Prospects of Mangroves as Medicinal Plants, Pesticide Pollution, Climate change and Desertification, Bio-Polymers.

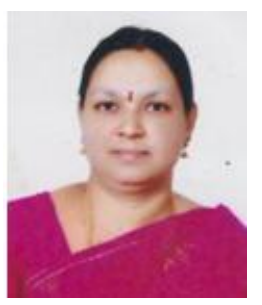

Dr. V. Subhashini, has obtained her MSc, MPhil, PhD Degrees from Acharya Nagarjuna University, Guntur, A.P, India. Presently she is working as a faculty in the department of Environmental Sciences, Acharya Nagarjuna University, Guntur, A.P, India. She has presented her research works in various seminars, conferences and she has so for published many research articles in national and international scientific journals. Areas of specialisation are, Removal of Fluorides, Phytoremediation of Heavy metals. 